\title{
ABORDAGEM RELACIONAL ENTRE FAMÍLIA E ESCOLA INCLUSIVA SOB AS PERSPECTIVAS DE PROFESSORES
}

\author{
RELATIONAL APPROACH BETWEEN FAMILY AND INCLUSIVE SCHOOL ON \\ TEACHERS' PERSPECTIVE.
}

\author{
Aline Maira da Silva ${ }^{1}$ \\ Leonardo Santos Amâncio Cabral ${ }^{2}$ \\ Morgana de Fátima Agostini Martins ${ }^{3}$
}

\begin{abstract}
Resumo
O presente artigo aborda a relação entre a família de alunos que compõem o público-alvo da Educação Especial e a escola. Com vistas a contribuir com as discussões sobre a temática, foi realizado um levantamento por meio da aplicação de questionário junto a 19 professoras de oito escolas municipais de Dourados/MS. No que tange à relação entre escola e família do aluno com deficiência, os resultados indicaram haver atividades de parceria entre seus atores, com participação, diálogo, respeito, execução de orientações, acompanhamento das atividades e valorização da socialização e aprendizagem desses alunos. Os dados sugerem, contudo, a necessidade de se fomentar o estabelecimento de uma relação mais efetiva e colaborativa entre os profissionais da escola e os membros familiares, de modo a possibilitar uma compreensão holística das necessidades, interesses e potencialidades dos alunos com deficiência e, concomitantemente, possibilitar aos familiares o acesso a informações sobre seus direitos, responsabilidades e recursos.
\end{abstract}

Palavras-chave: Inclusão Escolar. Parceria Colaborativa. Relação família-escola

\begin{abstract}
This article discusses the relationship between the family of students of the audience of Special Education and the school. In order to contribute to the discussions on this issue, a survey was conducted through a questionnaire with 19 teachers from eight municipal schools of Dourados / MS. Regarding the relationship between school and family of students with disabilities, the results suggested partnership activities between the actors, with the participation, dialogue, respect, implementation of the guidances, monitoring of activities and enhancement of socialization and learning of these students. The data suggest, however, the need to promote the establishment of a more effective and collaborative relationship between school community and family members in order to enable a holistic understanding of the

\footnotetext{
${ }^{1}$ Doutora em Educação Especial e professora do Programa de Pós-Graduação em Educação da Universidade Federal da Grande Dourados (PPGEdu/UFGD). Endereço eletrônico: alinesilva @ ufgd.edu.br

${ }^{2}$ Doutor e Pós-Doutor em Educação Especial, professor da Faculdade Educação da Universidade Federal da Grande Dourados (UFGD) e coordenador do Núcleo Multidisciplinar para a Inclusão e Acessibilidade da UFGD. Endereço eletrônico: leonardocabral@ufgd.edu.br

${ }^{3}$ Doutora em Educação Especial, Pós-Doutora em Educação, e professora do Programa de Pós-Graduação em Educação da Universidade Federal da Grande Dourados (PPGEdu/UFGD). Endereço eletrônico: morganamartins@ufgd.edu.br .
} 
needs, interests and potential of students with disabilities and, concomitantly, enable families to access information about their rights, responsibilities and resources.

Keywords: School Inclusion. Collaborative Partnership. Family-School Relation.

\section{INTRODUÇÃO}

No Brasil, os diversos contextos escolares são constantemente incitados a responderem às orientações políticas nacionais e internacionais que, há décadas, têm como prioridade a garantia de uma educação de qualidade para todos. Todavia, na prática, quando as diferentes realidades educacionais se deparam com uma enorme diversidade de necessidades inerentes à aprendizagem e ao desenvolvimento, bem como com a complexidade em atender à demanda advinda de um imperativo de caráter ideológico, sociopolítico, econômico e pedagógico, fica evidenciado o despreparo de seus profissionais e a sua ânsia pela identificação de alternativas eficazes que garantam a escolarização de todos, sobretudo a dos alunos que compõem o público-alvo da Educação Especial - PAEE (MAZZOTTA, 1996; JANNUZZI, 2004; MENDES, 2006).

Nesse contexto, a comunidade científica vem se debruçando em estudos que possam contribuir para a identificação de estratégias alternativas e/ou complementares que fomentem a construção de contextos inclusivos que vislumbrem a participação de diversos atores. Segundo indicam os estudos sobre inclusão ${ }^{4}$ escolar de Mendes, Vilaronga e Zerbato (2014, p.11), por exemplo, “os professores não deveriam trabalhar sozinhos, mas em equipes compostas de um grupo de pessoas cujas respostas e funções fossem derivadas de filosofias e objetivos mútuos". Além desses autores, podemos fazer referência aos estudos de Wood (1998) e Federico, Herrold e Venn (1999), o qual recomenda a adoção de modelos de colaboração entre professores, famílias e demais profissionais das escolas para o favorecimento da escolarização do PAEE.

À luz dessa perspectiva, a participação das famílias na vida escolar é destacada, em publicações técnicas, cartas e declarações internacionais resultantes de reuniões e conferências, como estratégia importante de apoio à aprendizagem dos alunos (CASTRO; REGATTIERI, 2009). No Brasil, o Estatuto da Criança e do Adolescente (ECA) determina

\footnotetext{
${ }^{4}$ Para evitar confusões conceituais decorrentes da redução do conceito de educação inclusiva à educação de estudantes com deficiências temos adotado por convenção o termo "inclusão escolar", em referência à questão específica da escolarização da população-alvo da Educação Especial, conforme definido pelas diretrizes políticas brasileiras.
} 
que "É direito dos pais ou responsáveis ter ciência do processo pedagógico, bem como participar da definição das propostas educacionais” (BRASIL, 1990, Artigo 53, Parágrafo único). A Lei de Diretrizes e Bases da Educação, por sua vez, preconiza "o fortalecimento dos vínculos de família, dos laços de solidariedade humana e de tolerância recíproca em que se assenta a vida social" (BRASIL, 1996, Artigo 32, Inciso IV). Em 2007, o Plano de Metas Compromisso Todos pela Educação, do Plano de Desenvolvimento da Educação - PDE, reforçou a importância da participação das famílias e da comunidade na busca da melhoria da qualidade da educação básica (BRASIL, 2007). Por sua vez, a Política Nacional de Educação Especial na Perspectiva da Educação Inclusiva (BRASIL, 2008) também orienta os sistemas de ensino a garantir a participação da família e da comunidade como uma das formas para atender as demandas dos alunos PAEE no ensino regular.

Entendendo, contudo, que as famílias são inseridas em uma comunidade, localizada em determinados territórios, costumes, valores e histórias, ao abordamos os componentes da interação entre a escola e a família, é recomendável optarmos por uma abordagem relacional que, segundo Castro e Regattieri (2009, p.15), apresenta "reciprocidade e influência mútua, considerando as especificidades e mesmo as assimetrias existentes nessa relação”. Segundo López et al. (2009), essa dinâmica relacional pode ser representada da seguinte maneira:

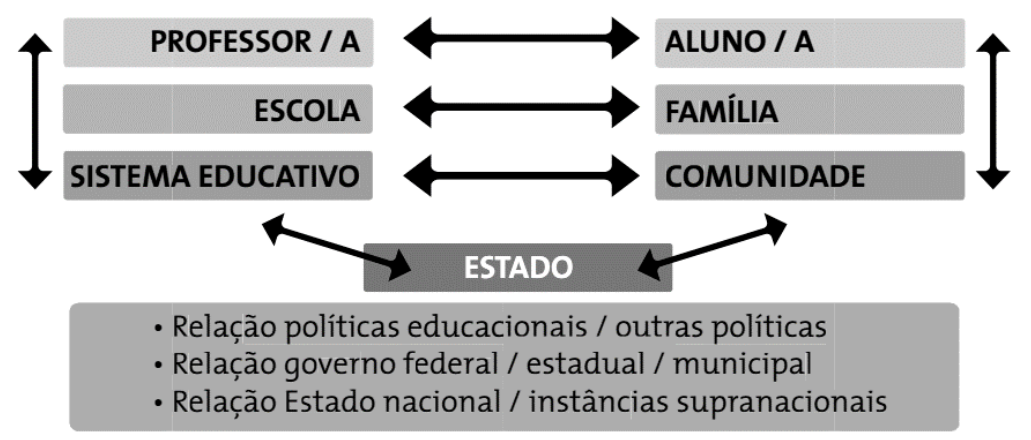

Fonte: López et al. (2009)

Nesse cenário, vale considerarmos a família como sendo, segundo Minuchin, Colapinto e Minuchin (1999), um sistema, no qual os membros tem contato direto entre si, estabelecendo uma relação de interdependência, ligados por laços emocionais e compartilhando histórias de vida. Segundo Maturana e Cia (2015, p. 350), "a família constitui o primeiro grupo social do qual o indivíduo faz parte, tendo normas, regras, crenças, valores, papéis próprios e previamente definidos, caracterizando-se como a primeira mediadora, por excelência, entre indivíduo e sociedade". Ainda, segundo as autoras: 
A escola é o segundo ambiente mediador entre indivíduo e ambiente. É no meio escolar que o saber culturalmente organizado e historicamente construído é transmitido de maneira mais sistemática. Além disso, é nesse ambiente que os alunos irão aprender novas formas de interação, comportamentos e serão apresentados a novos valores, tendo importância fundamental na socialização infantil, no desenvolvimento e na aprendizagem.

Particularmente no contexto educacional, podemos fazer referência à abordagem familiar sistêmica quando, conforme sugerem Turnbull e Turnbull (1997), possibilita-se aos profissionais da escola o estabelecimento de uma relação mais efetiva e colaborativa com os membros familiares o que, por sua vez, tem consequências positivas, sobretudo para aqueles com deficiências 5 .

Segundo Mendes (2006), para que a inclusão escolar seja bem-sucedida, a colaboração entre professores, familiares e outros profissionais da escola deve ser praticada. Por meio da colaboração é possível superar alguns obstáculos que impedem a plena participação e desenvolvimento do aluno PAEE no sistema regular de ensino e também alcançar o desenvolvimento pessoal e profissional de todos os envolvidos.

A parceria colaborativa com familiares proporcionada à família do aluno com deficiência os seguintes benefícios: os pais podem aprender maneiras novas e mais eficazes de disciplinar seus filhos, entender as intervenções realizadas na escola e contribuir com a realização das mesmas e diminuir a tensão sobre a criação dos filhos. Além disso, a colaboração entre família e escola é uma chance para os profissionais perceberem os familiares como parte da solução e não do problema (KAMPWIRTH, 2003).

Sobre a interação entre a escola e a família, Palomino e Gonzálves (2002) e Aiello (2002) descrevem sua importância no processo de compreensão das necessidades, interesses e potencialidades dos alunos com deficiência, além desta possibilitar aos familiares o acesso a informações sobre seus direitos, responsabilidades e recursos. O mais recente relatório publicado pela UNESCO, em colaboração com o MEC, destaca, em relação à escola e à família, que:

[...] ainda hoje mães, pais e os demais agentes escolares se encontram em condições bastante distintas dentro do processo educativo[...]. Essas duas instituições, que deveriam manter um espaço de interseção por estarem incumbidas da formação de um mesmo sujeito. [...] o insucesso escolar deveria suscitar a análise de causas dos problemas que interferiram na aprendizagem, avaliando o peso das condições escolares, familiares e individuais do aluno (CASTRO; REGATTIERI, 2009, p. 31).

\footnotetext{
${ }^{5}$ Segundo Mendes, Vilaronga e Zerbato (2014), “a compreensão que atualmente se tem acerca do objeto de Estudo da Educação Especial se encontra estreitamente vinculada às construções teóricas relacionadas à questão do seu principal objeto de estudo, o fenômeno das deficiências ou limitações que têm implicações educacionais" (pg. 21). Dada essa afirmação e, concordando com as referidas autoras, no presente artigo utilizaremos o termo "deficiências" de modo genérico em referência à população-alvo da Educação Especial.
} 
Frente a isso, entendemos a importância de investigarmos alguns fatores entendidos como sendo inerentes a esse processo: a) a parceria entre a escola e a família; b) a presença e a participação das famílias nas escolas; c) o diálogo entre as famílias e os professores; d) o fomento a oportunidades de orientações aos profissionais e aos familiares quanto às condições do aluno; e) a assiduidade do acompanhamento das famílias no processo de escolarização de seus filhos; f) os elementos associados diretamente à participação e à aprendizagem do aluno.

Considerando-se esses fatores e a importância de se envolver a família no processo de inclusão escolar do aluno PAEE, a presente pesquisa partiu do seguinte questionamento: Como se estabelece a relação de parceria entre familiares de alunos com deficiências matriculados no sistema regular de ensino e os profissionais de escolas de ensino fundamental de Dourados? Como essa parceria é caracterizada e avaliada na opinião dos professores regentes?

O objetivo da pesquisa foi identificar e descrever a parceria entre familiares de alunos com deficiência e professores dos primeiros anos do ensino fundamental de Dourados/MS, a partir da opinião dos professores regentes que atuam com alunos com deficiência.

\section{METODOLOGIA}

Foi realizada pesquisa de levantamento (COZBY, 2013), por meio da aplicação de questionário. O questionário foi composto por cinco questões sobre: a) dados pessoais e de formação dos professores; b) rede de apoio para a inclusão escolar do aluno com deficiência; c) parceria entre escola e família do aluno com deficiência. No presente artigo discutiremos os dados levantados pelas questões relacionadas com o último item investigado pelo instrumento - a parceria entre a escola e a família.

Participaram da pesquisa 19 professoras dos primeiros anos do ensino fundamental (primeiro ao quinto ano) de oito escolas municipais de Dourados/MS. Conforme mostra o Quadro 1, a idade das professoras variou entre 31 e 65 anos (média $=44,5$; mediana $=43$ ), sendo que uma das participantes optou por não informar sua idade. Grande parte das professoras $(68,4 \%)$ relatou experiência anterior com alunos com deficiência. 
Quadro 1 - Caracterização das professoras participantes da pesquisa.

\begin{tabular}{|c|c|c|c|c|}
\hline $\begin{array}{c}\text { Código } \\
\text { da escola }\end{array}$ & $\begin{array}{l}\text { Código da } \\
\text { professora }\end{array}$ & Idade & $\begin{array}{l}\text { Experiência anterior com } \\
\text { alunos com deficiência }\end{array}$ & Sexo \\
\hline \multirow{3}{*}{ A } & P1 & 31 & Não & $\mathrm{F}$ \\
\hline & $\mathrm{P} 2$ & 34 & Sim & $\mathrm{F}$ \\
\hline & P3 & 42 & Sim & $\mathrm{F}$ \\
\hline \multirow{4}{*}{ B } & $\mathrm{P} 4$ & 34 & Sim & $\mathrm{F}$ \\
\hline & $\mathrm{P} 5$ & 65 & Sim & $\mathrm{F}$ \\
\hline & P6 & 33 & Sim & $\mathrm{F}$ \\
\hline & P7 & 56 & Não & $\mathrm{F}$ \\
\hline \multirow{2}{*}{$\mathrm{C}$} & P8 & 32 & Não & $\mathrm{F}$ \\
\hline & P9 & --- & Sim & $\mathrm{F}$ \\
\hline $\mathrm{D}$ & $\mathrm{P} 10$ & 47 & Não & $\mathrm{F}$ \\
\hline \multirow{2}{*}{$\mathrm{E}$} & $\mathrm{P} 11$ & 55 & Sim & $\mathrm{F}$ \\
\hline & $\mathrm{P} 12$ & 60 & Sim & $\mathrm{F}$ \\
\hline \multirow{2}{*}{$\mathrm{F}$} & $\mathrm{P} 13$ & 45 & Não & $\mathrm{F}$ \\
\hline & P14 & 40 & Sim & $\mathrm{F}$ \\
\hline $\mathrm{G}$ & P15 & 49 & Sim & $\mathrm{F}$ \\
\hline \multirow{4}{*}{$\mathrm{H}$} & P16 & 43 & Sim & $\mathrm{F}$ \\
\hline & $\mathrm{P} 17$ & 43 & Sim & $\mathrm{F}$ \\
\hline & P18 & 50 & Não & $\mathrm{F}$ \\
\hline & P19 & 43 & Sim & $\mathrm{F}$ \\
\hline
\end{tabular}

Fonte: elaboração própria.

Como procedimento de coleta de dados, inicialmente foi realizado contato com a Secretaria Municipal de Educação de Dourados e, posteriormente, com a direção de oito escolas. Após anuência da direção das escolas, os professores foram convidados a participar da pesquisa. As professoras que concordaram em participar assinaram o Termo de Consentimento Livre e Esclarecido e preencheram o questionário.

\section{RESULTADOS E DISCUSSÃO}

Quando indagadas sobre a existência da parceria entre escola e família de alunos com deficiência, a maior parte das professoras $(68,4 \%)$ respondeu positivamente. Ao descrever sobre como a parceria é efetivada, as respostas mais citadas pelas professoras relacionaram-se à presença constante e participação dos familiares nas ações propostas pela escola $(46,1 \%)$ e ao diálogo frequente dos pais com as professoras $(38,5 \%)$. Os trechos selecionados a seguir ilustram as respostas das participantes: 
Contato frequente e participação em reuniões (P19).

Converso sempre com a mãe do aluno e acho que ela é participativa e colaborativa [...] (P16).

A mãe é bastante colaborativa, participativa e presente. Está em contato constante com as professoras e participa das reuniões (P18).

Ainda no que diz respeito ao diálogo entre família e escola, uma das professoras (P14) afirmou que a mãe e a professora responsável pela sala de recursos multifuncional conversam constantemente e que, na opinião dela, esse era um indicativo de parceria com os familiares.

Tal relato parece indicar que a professora regente não considera que é papel dela criar e manter uma via de comunicação com os familiares dos alunos com deficiência. Outra hipótese é que ela pode desconsiderar o quanto os familiares podem ser úteis para ampliar a participação do aluno no contexto regular de ensino. Essa indicação está fundamentada em trabalhos que buscaram conhecer e descrever o papel do professor da SRM pelo Brasil.

Mendes, Cia e Tannús-Valadão (2015), em apresentação de trabalhos que descreveram e analisaram o atendimento educacional especializado por todo o Brasil, observamos que os relatos de professores regentes atribuem ao professor especializado, responsável pela SRM, o papel de estabelecer parceria com as famílias. Seja por seu caráter especializado, seja pela maior flexibilidade do tempo e espaço escolar.

É importante destacar, ainda no que diz respeito ao diálogo entre família e escola, que a comunicação é um dos componentes essenciais para o estabelecimento da parceria entre os profissionais da escola e os familiares. Conforme apontam Borges, Gualda e Cia (2015, p. 179) "a escola necessita criar estratégias variadas e inovadoras de comunicação com os pais, para que a comunicação seja suficiente e efetiva ao transmitir informações relevantes sobre o desenvolvimento e aprendizagem da criança".

Embora com menor frequência, as professoras também mencionaram que a parceria com a família é efetivada quando os familiares comparecem à escola quando solicitado $(23,1 \%)$; quando seguem às orientações fornecidas pelos profissionais da escola $(13,4 \%)$; acompanham as atividades escolares realizadas pelo filho $(7,7 \%)$; demonstram preocupação com a educação do filho no que diz respeito à socialização e à aprendizagem $(7,7 \%)$.

\footnotetext{
A aluna é criada pela bisavó, que comparece à escola quando chamada e acompanha as atividades realizadas diariamente (P10).

O pai [...] acompanha as orientações realizadas (P11).

A mãe atende aos chamados da escola (P15)

A mãe segue as orientações fornecidas pela escola (P16).
} 
De modo geral, os resultados indicaram que as professoras entendem que cabe a família emitir comportamentos favorecedores e mantenedores na parceria. Foram relatados como exemplos de tais comportamentos: a presença na escola, a participação nas atividades desenvolvidas, a preocupação com o aluno e a colaboração com as professoras.

Com exceção da professora P6, cuja resposta demonstrou o movimento da escola em buscar o contato com a família, as demais participantes não mencionaram comportamentos, descritos pela literatura da área, que os profissionais da escola precisam emitir para aproximar da escola os familiares de alunos com deficiência como a disposição dos profissionais para se reunir com familiares em horários flexíveis e para se envolver com a vida do aluno e com o bem-estar do mesmo (NELSON; SUMMERS; TURNBULL, 2004); facilitar a comunicação com a família por meio de caderno de comunicação (SILVA; MENDES, 2008); demonstrarem sensibilidade para estabelecer um bom vínculo com os pais, de modo a alcançar a confiança dos mesmos (MCWILLIAM; TOCCI; HARBIN, 1998); comunicar-se com os familiares de modo claro, amistoso e acessível (SILVA; MENDES, 2008); demonstrar-se receptivo e imparcial (BLUE-BANNING et al., 2004)

O relato das professoras sinaliza que, embora exista uma relação entre a família e a escola, tal relação não pode ser nomeada como parceria colaborativa, caracterizada principalmente pela equivalência entre os participantes, existência de um objetivo comum e compartilhamento de recursos, assim como de responsabilidades (MENDES, 2006). A resposta de uma das professoras (P13) demonstra claramente a ausência da colaboração, ao afirmar que a parceria não é significativa, dada a pequena participação dos familiares.

Outro exemplo foi o apontamento, por parte das participantes, do comportamento de seguir as orientações dos profissionais como um indicador de parceria entre família e escola. O comportamento mencionado é característico de um modelo de relação denominado modelo de transplante, no qual o papel dos profissionais é transplantado para o contexto familiar, ou seja, a família torna-se responsável por desenvolver ações em casa (treinos e exercícios, por exemplo), conforme as orientações que lhes são fornecidas (PANIAGUA, 2004).

Tal modelo reforça a tradicional submissão dos familiares em relação aos profissionais envolvidos de forma direta e indireta com a educação do aluno com deficiência e é incompatível com a perspectiva da colaboração. De acordo com Silva (2007, p. 98), "talvez os familiares não estejam íntimos de modelos mais caracterizados pela colaboração, já que eles ainda se colocam como co-educadores, seguindo as orientações fornecidas pelos profissionais $[\ldots] "$. 
Os resultados deixam claro uma relação de desequilíbrio, na qual os profissionais ocupam uma posição de superioridade em relação aos familiares. Conforme reflete Araújo (2011, p. 152),

\begin{abstract}
Algumas barreiras deveriam ser transpostas para se efetivar o trabalho com famílias de pessoas com deficiências. Uma delas é a visão subestimada dos profissionais a respeito da capacidade da família, uma visão superestimada do profissional, a despeito do seu próprio trabalho e, aliado a isso, ainda existe a crença, por parte das famílias, que o trabalho profissional é soberano e inquestionável. Dessa forma, o empoderamento das famílias de pessoas com deficiência se torna necessário para uma mudança desse cenário nacional em busca de uma valorização das famílias.
\end{abstract}

Resultados diferentes foram descritos por Borges, Gualda e Cia (2015, 180), em estudo cujo objetivo foi descrever a relação entre escola e familiares de alunos matriculados na Educação Infantil, segundo a opinião dos professores. Segundo as autoras, as professoras participantes demonstraram conhecimento sobre o quanto o seu trabalho e apoio "[...] é de extrema importância aos pais de alunos PAEE; assim, buscam informá-los sobre questões relevantes na tentativa de orientá-los, tranquilizá-los e esclarecer sobre quaisquer dúvidas que possam surgir". Finalmente, cabe destacar que apenas duas professoras demonstraram em suas respostas reconhecer que a relação entre família e escola tem impactos positivos para o desenvolvimento e a aprendizagem do aluno com deficiência:

Estamos sempre em contato com a família, pois acreditamos que sem esse apoio o desenvolvimento do aluno fica limitado e dificulta o trabalho da escola (P6).

A família é muito importante nesse processo. A família do meu aluno é participativa em tudo que propomos, o que faz acontecer o amadurecimento dele e o permite compreender seu ambiente escolar (P8).

Por outro lado, os resultados levantados por Borges, Gualda e Cia (2015) indicam que as professoras participantes reconhecem que cabe aos profissionais da escola buscar meios para buscar a participação dos familiares, sendo que tal comportamento foi mencionado como um dos fatores escolares que poderiam influenciar o sucesso da criança PAEE no ensino regular.

Conforme explica Silva (2007, p. 10), "por força da tradição da área os profissionais continuam prestando serviços baseados em modelos centrados nas crianças e nem sempre encontram o caminho para fazer da família uma parceira". Mesmo considerando como importante a participação da família, o contexto escolar ainda é caracterizado pelo comportamento de agir a partir de convites, propostas, pedidos da escola. Não há demonstrações de movimentos em relação à escuta dos familiares e de suas necessidades, com vista à elaboração de ações conjuntas. 


\section{CONSIDERAÇÕES FINAIS}

Embora haja um consenso sobre a importância da parceria entre familiares e profissionais (OMOTE, 1980; TURNBULL; TURNBULL, 1997; MARTINS, 2006; MENDES e SILVA, 2008; ARAÚJO, 2011), existem alguns obstáculos para que ela seja alcançada. Um desses obstáculos é, segundo Minuchin, Colapinto e Minuchin, (1999), o fato de que muitos profissionais, ao focalizarem sua ação no indivíduo, consideram o atendimento às famílias um trabalho extra que pode ser dispensado para reduzir a sobrecarga de trabalho. Assim, a atenção às famílias na prática nem sempre é tida como fundamental e os profissionais não são incentivados a mudar essa situação.

Este trabalho buscou identificar e descrever a parceria entre familiares de alunos com deficiência e professores dos primeiros anos do ensino fundamental de Dourados/MS tendo como referência a opinião dos professores regentes que atuam com alunos com deficiência.

Os dados obtidos apontaram para muitas direções, mas infelizmente, todas distantes de uma proposta de parceria colaborativa e, mais propensa à inclusão escolar efetiva desses alunos.

As estratégias para o trabalho com famílias devem levar em consideração o fato de que a comunicação é um processo de duas vias, no qual profissionais devem ser sensíveis para ouvir primeiro às necessidades e interesses dos pais, e então, juntamente com eles, formar um plano para ir ao encontro dessas necessidades.

Ao contrário disso, a ideia de parceria ainda é vista como algo realizado apenas pelo professor especializado, da SRM. Esse parece ser um ranço de nossa trajetória na escola especial, pois ainda permanece a ideia de que o trabalho com pais está voltado para as crianças que "tem problemas", que necessitam de atenção diferenciada, de serviço diferenciado. A família é coadjuvante nesse processo.

A família não é parte da escola. Ela ainda é tratada como convidada e é acionada quando há algo específico a ser resolvido, como reuniões bimestrais para entrega de notas, solicitações de autorizações e, quando há a necessidade de intervenções médicas, por exemplo para obtenção do laudo clínico. Também há a presença do vocativo clássico para a solução de problemas de comportamentos.

Nessa mesma direção, conforme problematizam Nunes, Saia e Tavares (2015), 
Enfim, podemos perceber um fogo cruzado entre escola e família. Fogo cruzado sem vencedores. É importante assumirmos que, muitas vezes, profissionais da educação e família são representantes de classes sociais diferentes e suas falas e atitudes denunciam, ainda, um abismo de comunicação, em que cada parte espera que a outra faça aquilo que não conseguiu realizar (NUNES; SAIA; TAVARES, 2015. p. 1.116).

Outra questão que parece emergir dos comentários das professoras é a ausência de estratégias que favoreçam o contato entre os pais, o que seria enriquecedor para a troca de experiências afetivas e mesmo para o empoderamento dessas pessoas frente à condição de seus filhos.

A parceria entre família e escola promove muitos benefícios, apontados por Aiello (2000), que ainda afirma que a família pode ficar mais informada em relação aos seus direitos, responsabilidades e recursos e também mais esclarecida sobre a deficiência apresentada por um de seus membros.

Segundo Silva e Dessca (2001) a estratégia de enfrentamento mais usada pelos pais em relação à compreensão e atuação junto ao seu filho com deficiência é a de buscar por informações sobre a deficiência e as fantasias de satisfação de desejos, de como eles poderiam lidar com as situações difíceis e de como seria o progresso no desenvolvimento de sua criança. Uma das variáveis importantes para que as famílias atuem em parceria com a escola é o suporte social recebido e percebido pelos familiares.

A escuta positiva e o respeito às necessidades e anseios dos familiares foi assunto muito discutido em trabalhos da área que apontam, como elementos amplificadores da participação e do compromisso das famílias, ações que favoreçam o desenvolvimento e a aprendizagem de seus filhos. Pais atendem e respondem melhor às atividades que tenham sido planejadas em conjunto (MARTINS, 2006).

Quando a escola, na figura do professor regente, não se coloca como responsável em criar estratégias e espaços de discussões, torna-se insipiente a promoção de parcerias com as famílias e com outros profissionais, sobretudo no que diz respeito à sua relação com o professor da SRM.

Identifica-se, ainda, diversas dificuldades que podem inibir o estabelecimento de parcerias entre os familiares e os profissionais da comunidade escolar, particularmente no que se refere àqueles que oferecem o atendimento educacional especializado. Dentre esses fatores, Martins (2006) indica: serviços de transporte precários, além de os horários serem incompatíveis com a oferta desses serviços, considerando-se que, muitas vezes, esses são 
ofertados no turno em que os familiares dos alunos com deficiências, por vezes, encontram-se impossibilitados de buscá-los.

Em contrapartida, Maturana e Cia (2015) identificaram em aprofundada revisão bibliográfica que os estudos de Glat (1996), Dessen e Polônia (2005, 2007) e Carvalho indicam que o sucesso na relação entre família-escola tem sido apontado na literatura como um dos principais fatores facilitadores da inclusão escolar, indicando, dentre eles, o envolvimento e desempenho acadêmico do aluno, sua adesão às normas e rotinas da escola são atribuídas, em parte, à participação ou ausência da família em reuniões de pais e atividades escolares, o apoio direto e sistemático da família que investe nos filhos.

Frente a isso, podemos sugerir que esses fatores podem contribuir para o sucesso ou o insucesso da aproximação, participação e colaboração entre as partes envolvidas e, portanto, podemos concluir que ainda que a importância e a necessidade do estabelecimento da parceria entre família e escola esteja descrita e preconizada não somente nas legislações nas políticas de inclusão escolar, mas também nas estratégias escolares voltadas a concretizar essa aproximação, na qual vislumbre a efetivação da escolarização do público-alvo da Educação Especial, envolvendo-se as diversas esferas sociais que envolvem esse processo, sobretudo as comunidades escolares e familiares.

\section{REFERÊNCIAS}

AIELLO, A.R. Família inclusiva. In: PALHARES, M.S.; MARTINS, S.C.T. (Org.). Escola inclusiva. São Carlos, SP: EdUFSCar, 2002.

ARAÚJO, R. M. Empoderamento pais para a luta pelos direitos de seus filhos com deficiência: pesquisa-ação emancipatória. 2011. 187f. Tese (Dourorado em Educação Especial). Universidade Federal de São Carlos. São Carlos, 2011.

BLUE-BANNING, M., et al. Dimensions of family and professional partnerships: constructive guidelines for collaboration. Exceptional children, v. 70, n. 2, p. 167-84, 2004.

BORGES, L.; GUALDA, D. S.; CIA, F. Relação Família e Escola e Educação Especial: Opinião de Professores. Educação: Teoria e Prática, v. 25, n.48, p. 168-185, 2015.

BRASIL. Presidência da República. Congresso Nacional. Lei $n^{\circ} 9.394$, de 20 de dezembro de 1996. Brasília, 1996. Disponível em:

<http://portal.mec.gov.br/seesp/arquivos/pdf/lei9394_ldbn1.pdf>. Acesso em: 16 fev. 2016.

BRASIL. Presidência da República. Decreto no 6.094de 24 de Abril de 2007. Plano de Metas Compromisso Todos pela Educação. Brasília, 2007. Disponível 
em:http://www.planalto.gov.br/ccivil_03/_ato2007-2010/2007/decreto/d6094.htm. Acesso em: 20 fev. 2016.

BRASIL. MEC/SEESP. Política Nacional de Educação Especial na Perspectiva da Educação Inclusiva. Brasília, 2008.

Senado Federal. Subsecretaria de Informações. Lei $n^{o}$ 8.068, de 13 de julho de 1990. Brasília, 1990. Disponível em:

<http://www6.senado.gov.br/legislacao/ListaPublicacoes.action?id=102414>. Acesso em: 16 fev. 2016.

CARVALHO, M. E. P.. Relações entre família e escola e suas implicações de gênero.

Cadernos de Pesquisa, São Paulo, 110, pp. 143-155, 2000.

CASTRO, J. M.; REGATTIERI, M. Interação escola-família: subsídios para práticas escolares. Brasília: UNESCO, MEC, 2009. 104 p.

COZBY, P. C. Métodos de pesquisa em ciências do comportamento. Tradução de Paula Inez Cunha Ganade e Emma Otta. São Paulo: Atlas, 2003.

DESSEN, M. A.; POLONIA, A. C.. Em busca de uma compreensão das relações entre família e escola. Psicologia Escolar e Educacional, v. 9, n. 2, pp.303-312, 2005.

A família e a escola como contextos de desenvolvimento humano. Paidéia, Ribeirão Preto, v. 17, n. 36, 21-32, 2007.

FEDERICO, M. A.; HERROLD, W. G.; VENN, J. Helpful tips for successful inclusion: a checklist for educators. Teaching Exceptional Children (TEC), Arlington, v. 32, n. 1, p. 7682, 1999.

GLAT, R.. O papel da família na integração do portador de deficiência. Revista Brasileira de Educação Especial, v. 2, n. 4, 111- 118, 1996.

JANUZZI, G. M. A educação do deficiente no Brasil: dos primórdios ao início do século XXI. Campinas: Editora Autores Associados, 2004.

KAMPWIRTH, T. J. Collaborative consultation in the schools: effective practices for students with learning and behavior problems. New Jersey: Pearson Education, 2003.

LÓPEZ, N. et al. De relaciones, actores y territorios: hacia nuevas políticas entorno a la educación en América Latina. LÓPEZ, N. (Coord.). IIPE/UNESCO: Buenos Aires, 2009.

MARTINS, M. F. A. Efeitos de um programa de atenção diversificado às mães de alunos severamente prejudicados. 2006. 165f. Tese Doutorado - Programa de Pós Graduação em Educação Especial: UFSCar: São Carlos, 2006. 
MATURANA, A. P. P. M.; CIA, F. Educação Especial e a Relação Família - Escola: Análise da produção científica de teses e dissertações. Revista Quadrimestral da Associação Brasileira de Psicologia Escolar e Educacional, SP, v. 19, n. 2, Maio/Ago., p. 349-358, 2015.

MAZZOTTA, M. J. S. Educação Especial no Brasil: história e políticas públicas. 5. ed. São Paulo: Cortez Editora, 1996. 208 p.

McWILLIAM, R.A.; TOCCI, L.; HARBIN, G.L. Family-centered services: service providers' discourse and behavior. Topics in Early Childhood Special Education, vol. 18, n. 4, p. 206$221,1998$.

MENDES, E. G.; VILARONGA, C. A. R.; ZERBATO, A. P. Ensino Colaborativo como apoio à inclusão escolar: unindo esforços entre educação comum e especial. São Carlos: EdUFSCar, 2014. 160p.

MENDES, E.G. Colaboração entre ensino regular e especial: o caminho do desenvolvimento pessoal para a inclusão escolar. In: MANZINI, J.E. (Org.). Inclusão e acessibilidade. Marília: ABPEE, 2006.

MENDES; E. G.; CIA, F.; TANNÚS-VALADÃO, G. Organização e funcionamento do atendimento educacional especializado. In: MENDES; E. G.; CIA, F.; TANNÚS-

VALADÃO, G. Inclusão escolar em foco: organização e funcionamento do atendimento educacional especializado. Marília: ABPEE. 2015.

MINUCHIN, P.; COLAPINTO, J.; MINUCHIN, S. Trabalhando com famílias pobres. Porto Alegre: Artmed editora, 1999.

NELSON, L.G.L.; SUMMERS, J.A.; TURNBULL, A.P. Boundaries in family-professional relationship: implications for special education. Remedial and Special Education, vol.25, n. 3, p. 153-165, 2004.

NUNES, S. S.; SAIA, A. L.; TAVARES, R. E. Educação Inclusiva: Entre a História, os Preconceitos, a Escola e a Família. IPsicologia: Ciência e Profissão, v. 35, n. 4, p. 11061119, 2015.

OMOTE, S. Reações de mães de deficientes mentais ao reconhecimento da condição dos filhos afetados: um estudo psicológico. Dissertação (Mestrado). Universidade de São Paulo, São Paulo, 1980.

PALOMINO, A. S.; GONZÁLVES, J. A. T. Educacion especial: centros educativos y profesores ante la diversidad, Madrid: Psicología Pirámide, 2002.

PANIAGUA, G. As famílias de crianças com necessidades educativas especiais. In: COLL, C., MARCHESI, A. et al., tradução de Fátima Murad, Desenvolvimento psicológico e educação: transtornos de desenvolvimento e necessidades educativas especiais, volume $3,2^{\mathrm{a}}$ edição, Porto Alegre: Artmed, 2004.

SILVA, A. M.; MENDES, E. G. Família de crianças com deficiência e profissionais: componentes da parceria colaborativa na escola. Revista Brasileira de Educação Especial, v. 14, n. 2, p. 217-234, 2008. 
SILVA, N. L. P.; DESSCA, M. A. Deficiência Mental e Família: Implicações para o Desenvolvimento da Criança. Psicologia: Teoria e Pesquisa. 17, 133-141, 2001.

TURNBULL, A.P.; TURNBULL, H.R. Families, professionals, and exceptionality: a special partnership, $3^{\text {a }}$ ed., New Jersey: Prentice-Hall, 1997. 